\title{
BMI
}

\section{Chest physiotherapy}

\author{
May be harmful in some patients
}

Chest physiotherapy in the form of postural drainage, percussion, and vibration is carried out in the hope that removing secretions will improve respiratory function and prevent collapse of the lung. ${ }^{1}$ One of the earliest papers advocating chest physiotherapy appeared in 1915 and was an uncontrolled study conveying only subjective impressions about the recovery of patients. ${ }^{2}$ By the time objective data became available chest physiotherapy was already widely used. Yet several controlled trials have shown that the benefits are far from clearcut and that harm may be done to some patients. The widespread use of chest physiotherapy has thus been questioned, ${ }^{3-7}$ and attempts have been made to clarify its place in patients with both acute and chronic respiratory problems. ${ }^{8.9}$

Studies that show the value of physiotherapy have usually been conducted in patients who produce excessive sputummore than $30 \mathrm{ml}$ daily. ${ }^{10-13}$ Postural drainage, percussion, and vibration produced improvements in either lung function tests ${ }^{1011}$ or the amount of sputum expectorated. ${ }^{12}{ }^{13}$ Bateman et al claimed that physiotherapy cleared radioaerosol particles from all compartments of the lung, including the periphery. ${ }^{12}$ Their use of the term periphery was, however, misleading as it referred to the lateral $40 \%$ of the area on an isotope scan and thus included parts of the main bronchi.

Several studies have shown that chest physiotherapy was either not useful ${ }^{1+15}$ or positively harmful ${ }^{1617}$ in patients who did not produce excessive sputum. For example, patients with an acute exacerbation of chronic bronchitis but without copious sputum production were monitored for changes in the volume of sputum expectorated daily, temperature, and arterial blood gas tensions. ${ }^{14}$ There was no difference between controls and those given physiotherapy. ${ }^{1+}$ Physiotherapy in similar patients either has no effect on lung function tests ${ }^{15}$ or causes a fall in the forced expiratory volume in one second. ${ }^{16} 17$ Campbell et al postulated that postural drainage, percussion, and vibration induced bronchospasm, and by giving a $\beta_{2}$ agonist before physiotherapy they were able to blunt the decrease in the forced expiratory volume in one second. ${ }^{16}$ Wollmer et al used a radioaerosol technique to show that chest percussion did not enhance particle clearance from either central or peripheral lung compartments. ${ }^{17}$

That postural drainage, percussion, and vibration are unlikely to clear secretions from the lung periphery has been confirmed by studies of patients with acute primary pneumonia. ${ }^{18}{ }^{19}$ Graham and Bradley found no difference in the speed of resolution of signs on chest radiographs or duration of fever or hospital stay between a control group and a group given physiotherapy. ${ }^{18}$ In the other study regular chest physiotherapy prolonged the duration of fever and increased the hospital stay of patients when compared with advice on expectoration and deep breathing. ${ }^{19}$

Further evidence that physiotherapy is most effective at clearing secretions from the main bronchi has come from a study of patients with acute lobar collapse. ${ }^{20}$ The success rate in regaining lung volume was strongly related to whether there was an air bronchogram: the resolution rate was only a quarter with a bronchogram compared with almost $90 \%$ with no bronchogram. The explanation was that with such a bronchogram there was distal collapse but no sputum plug, whereas no bronchogram meant that sputum had blocked a bronchus and caused secondary collapse.

Coughing exercises are as effective as postural drainage, percussion, and vibration in clearing sputum from patients with cystic fibrosis. ${ }^{21}$ In patients with chronic bronchitis coughing exercises have been investigated with radioaerosol techniques and have produced as much central lung clearance as physiotherapy ${ }^{22}$ and greater total clearance than no treatment. ${ }^{23}$ One of the mechanisms by which cough affects sputum clearance is known as "two phase gas-liquid flow"the transfer of momentum and energy from the high speed flow of air to the mucus that lines the bronchi. The high transmural pressures produced during coughing lead, however, to dynamic compression of the airways, which may inhibit mucociliary clearance. ${ }^{2+}$ The "forced expiration technique" was introduced to circumvent this problem and requires the patient to expire forcefully from middle to low lung volumes while maintaining an open glottis. In patients with chronic bronchitis who produce copious sputum this technique has led to greater clearance of inhaled radiolabelled particles than both regimented coughing ${ }^{25}$ and percussion and vibratory exercises. ${ }^{26}$ The amount of sputum obtained was further increased when the technique was combined with postural drainage. In this combination the technique also cleared more sputum and in less time than conventional physiotherapy in patients with cystic fibrosis. ${ }^{27}$ These patients can practise the forced expiration technique without having to rely on others for assistance.

Enhancing sputum production in patients with respiratory disease is a desirable aim, even though the long term benefits are uncertain. Several studies have, however, highlighted the 
possibility of short term hypoxaemia lasting up to 30 minutes after physiotherapy. ${ }^{28-36}$ Most patients tolerate this hypoxia, but postural drainage, percussion, and vibration must be employed with particular care in critically ill patients ${ }^{29.31}$ and in those with low blood concentrations of oxygen. ${ }^{28}{ }^{30-32}$

Thus because of the risk of causing either bronchospasm or short term hypoxaemia postural drainage, percussion, and vibration should be used only in patients in whom its value has been proved. The forced expiration technique combined with postural drainage should be strongly considered as an alternative.

Senior Registrar,

D S SELSBY

Department of Anaesthesia,

General Infirmary,

Leeds LS1 3EX

1 Palmer KNV, Sellick BA. The prevention of postoperative pulmonary atelectasis. Lancet $1953 ; i: 164-8$

2 MacMahon C. Breathing and physical exercises for use in cases of wounds in the pleura, lung and diaphragm. Lancet 1915;ii: 769-70.

Demers R. Contraindications for chest physiotherapy. Chest 1986;89:962-3.

4 Anonymous. Chest physiotherapy under scrutiny [Editorial]. Lancet 1978;ii:1241.

4 Anonymous. Chest physiotherapy under scrutiny [Editorial]. Lancet 1978;i:

6 Petty TL, Jones NL, Mellins RB. Proceedings of the conference on the scientific basis of respiratory therapy. Am Rev Respir Dis 1974;110:129-42.

Lyle CB, Bianchi RF, Harris JH. Evaluation of respiratory physical therapy. N Engl f Med 1979;301:665

8 Sutton PP, Pavia D, Bateman JRM, Clarke SW. Chest physiotherapy: a review. Eur f Respir Dis 1982;63:188-201.

Kirrilof LH, Gregory RO, Rogers RM, Mazzocco MC. Does chest physical therapy work? Chest 1985;88:436-44.

10 Cochrane GM, Webber BA, Clarke SW. Effects of sputum on pulmonary function. Br Med 7 1977;ii:1181-3.

11 Tecklin JS, Holsclaw DS. Evaluation of bronchial drainage in patients with cystic fibrosis. Phys Ther 1975;55:1081-4.

12 Bateman JRM, Newman SP, Daunt KM, Pavia D, Clarke SW. Regional lung clearance of excessive lung secretions during chest physiotherapy in patients with stable chronic airways obstruction. Lancet 1979;i:294-7.
13 May DB, Munt PW. Physiologic effects of chest percussion and postural drainage in patients with stable chronic bronchitis. Chest 1979;75:29-32

14 Anthonisen $P$, Riis $P$. The value of lung physiotherapy in the treatment of acute exacerbations in chronic bronchitis. Acta Med Scand 1964;175:715-9.

15 Newton DAG, Stephenson A. Effect of physiotherapy on pulmonary function. Lancet 1978;i:228-9. 16 Campbell AH, O'Connell JM, Wilson F. The effect of chest physiotherapy on the FEV 1 in chronic bronchitis. Med $\mathcal{F}$ A ust 1975;i:33-5.

17 Wollmer P, Ursing K, Midgren B, Eriksson L. Inefficiency of chest percussion in the therapy of chronic bronchitis. Eur f Respir Dis 1985;66:233-9.

18 Graham WGB, Bradley DA. Efficiency of chest physiotherapy and intermittent positive pressure breathing in the resolution of pneumonia. $N$ Engl f Med 1978;299:624-7.

19 Britton S, Bejstedt M, Vedin L. Chest physiotherapy in primary pneumonia. Br Med $\mathcal{J}$ 1985;290:1703-4

20 Marini JJ, Pierson DJ, Hudson LD. Acute lobar atelectasis: a prospective comparison of fiberoptic bronchoscopy and respiratory therapy. Am Rev Respir Dis 1979;119:971-8.

21 DeBoeck C, Zinman R. Cough versus chest physiotherapy. Am Rev Respir Dis 1984;129:182-4.

22 Bateman JRM, Newman SP, Daunt KM, Sheahan NF, Pavia D, Clarke SW. Is cough as effective as chest physiotherapy in the removal of excessive tracheobronchial secretions? Thorax 1981;36:683-7.

23 Oldenberg JR, Dolovich MB, Montgomery JM, Newhouse MT. Effects of postural drainage, exercise, and cough on mucous clearance in chronic bronchitis. Am Rev Respir Dis 1979;120 $739-45$

24 Smalldone GC, Itoh H, Swift DL, Wagner HN. Effect of flow-limiting segments and cough on particle deposition and mucociliary clearance in the lung. Am Rev Respir Dis 1979:120:747-58.

25 Sutton PP, Parker RA, Webber BA. Assessment of the forced expiration technique, postural drainage and directed coughing in chest physiotherapy. Eur f Respir Dis 1983;64:62-8.

26 Sutton PP, Lopez-Vidriero MT, Pavia D. Assessment of percussion, vibratory-shaking and breathing exercises in chest physiotherapy. Am Rev Respir Dis 1985;66:147-52.

27 Pryor JA, Webber BA, Hodson ME, Baten JC. Evaluation of the forced expiration technique as an adjunct to postural drainage in the treatment of cystic fibrosis. Br Med f 1979;ii:417-8.

28 Gormezano J, Branthwaite MA. Pulmonary physiotherapy with assisted ventilation. Anaesthesia 1972;27:249-57.

29 Connors AF, Hammon WE, Martin RJ, Rogers RM. Chest physical therapy: the immediate effect on oxygenation in acutely ill patients. Chest 1980;78:559-64.

30 Huseby J, Hudson L, Stark K, Tyler M. Oxygenation during chest physiotherapy. Chest 1976;70:430.

31 Tyler $M$, Hudson L, Grose B, Huseby J. Prediction of oxygenation during chest physical therapy. Am Rev Respir Dis 1980;121(suppl):218.

32 McDonnell T, McNicholas WT, Fitzgerald MX. Hypoxaemia during chest physiotherapy in patients with cystic fibrosis. Ir f Med Sci 1986;155:345-8

33 Gormezano J, Branthwaite MA. Effects of physiotherapy during intermittent positive pressure ventilation. Anaesthesia 1972;27:258-64.

34 Holloway R, Adams EB, Desai SD, Thambiran AK. Effect of chest physiotherapy on blood gases of neonates treated by intermittent positive pressure respiration. Thorax 1969;24:421-6.

35 Fox WW, Schwartz JG, Schaffer TH. Pulmonary physiotherapy in neonates: physiologic changes and respiratory management. F Pediatr 1978;92:977-81.

36 Walsh CM, Bada HS, Korones SB, Carter MA, Wong SP, Arheart K. Controlled supplemental oxygenation during tracheobronchial hygiene. Nurs Res 1987;36:211-5.

\section{Control of meningococcal disease}

\section{Chemoprophylaxis for carriers and some contact groups}

Though small, the risk of meningococcal infection in household contacts of a patient with the disease is significantly greater in the general population. ${ }^{12}$ Two studies published this week (p 555 and p 569) confirm this, adding that, though the risk is greatest within the first few days after contact, ${ }^{3}$ it may persist for several months.

There are two possible chemoprophylactic strategies for managing this increased risk. Firstly, phenoxymethylpenicillin is offered to close contacts for seven days. A Norwegian study has shown that, though this regimen was protective for the duration of treatment, subsequent household cases occurred later, presumably because of a continued exposure to the carriers, who may have been the source of infection in the index case. ${ }^{+}$Secondly, the alternative strategy (which we recommend) is to try to eliminate the carriage of meningococci in the close contacts to reduce transmission to susceptible people..$^{5-7}$

Sulphonamides have been used to reduce transmission, but many of the strains producing disease in the United Kingdom are resistant, and consequently rifampicin is the best antibiotic to use (adults $600 \mathrm{mg}$ every 12 hours for two days; children aged over 1 year $10 \mathrm{mg} / \mathrm{kg}$ every 12 hours for two days; children below 1 year $5 \mathrm{mg} / \mathrm{kg}$ every 12 hours for two days). Ciprofloxacin as a single oral dose of $500 \mathrm{mg}$ is an alternative for adults but is not yet licensed in the United Kingdom for children and adolescents. Ceftriaxone in a single dose of $250 \mathrm{mg}$ intramuscularly is also effective and is not contraindicated in pregnancy. ${ }^{8}$
Rifampicin should be offered as soon as possible (and ideally simultaneously) to those living with the patient, to anybody who has kissed the patient in the 10 days before admission, and to convalescent patients before discharge from hospital. ${ }^{7}$ Contacts receiving rifampicin must be told about its side effects: discoloration of soft contact lenses; interaction with oral contraceptives; and colouring urine, saliva, and other body secretions orange red. These side eft :cts are not contraindications.

Bacterial resistance to rifampicin may emerge after chemoprophylaxis and, as found by Cooke et al, secondary cases may be due to meningococcal strains resistant to rifampicin. Hence the use of this antibiotic should be restricted to contact groups known to be at increased risk. Infection among hospital staff contacts of cases of meningococcal meningitis or septicaemia is rare, and such contacts are considered to be at increased risk and to require prophylaxis only if mouth to mouth contact has occurred. (The possible nosocomial spread from a patient with a respiratory tract infection reported by Eriksen and colleagues ( $p$ 568) arose out of an unusual set of circumstances.) School contacts do not require chemoprophylaxis unless more than one related case occurs in the school. Nevertheless, special circumstances may justify the wider use of chemoprophylaxis, such as the attendance of the index case in the 10 days before the onset of the illness at a party at which young children or teenagers are present or at a nursery school or day care centre, which may resemble a "household" setting. Taking swabs from the household and 